\title{
How to Improve the Safety of Post-90s College Students Tourism Education
}

\author{
$\mathrm{Na} \mathrm{Li}$ \\ School of engineering and technology, Jilin Agricultural University, Changchun 130118, China \\ 350202380@qq.com
}

\author{
Keywords: Instructor, College Students, Travel Safety
}

\begin{abstract}
The frequent occurrence of college student's tourism safety accidents sounded the alarm for every well educated people. The Counselor is the main embodiment of the university student safety education, they pay attention to strengthen the tourism safety education in college students' safety education. This paper puts forward the corresponding countermeasures from the ways of strengthening college student's tourism safety education counselor and improving student's awareness of travel security.
\end{abstract}

\section{Introduction}

With the rising national economic development and people's consumption level, the residents' demand for tourism consumption is growing, so does the college students tourism group. The post90s college students have personality independence with a passion on adventure. In recent years, college students travel safety incidents have occurred frequently: In December 2010, Fudan University students were in distress in Huangshan; On April 30, 2011, four college students play in Qingdao were in distress, two of whom were swept away by the waves and only one was rescued; On June 4, 2011, 38 students from four universities in Xi'an, the spontaneous organization of a companion travel, on the way back to Xi' an, the bus pulled into the ditch, one person died; On January 9, 2012, a tragedy happened in "Happy Snow World" ski resort of Dalian City, Liaoning Province. A 20-year-old college student Cao of Dalian University skied out of the snow trail and hit the column. Unfortunately, the final rescue was invalid and he died; on the evening of March 1, 2012, six Hubei college students played next to the river, one of the students accidentally fell into the cold river. The companions around quickly rescued him, but the results were also pulled into the water unfortunately. The two were washed away and the body did not salvage out till today; During the Tomb-sweeping day in 2012, in Suzhou Xishan scenic area, a speedboat carrying eight people collided with the towing cables between the two cargo ships, resulting in the death of the four college students including the part-time tour guides, and the other four were injured.

A trip is a journey of life. Paying no attention to tourism safety means you treat life as a trifle or a life bet. A vivid life disappears suddenly, it is a signing. Almost every summer and winter vacation and small holidays, there will be travel safety accidents of the college students, ranging from lost, injured, even to death. Similar tragedies are still frequently staged. As an instructor, he had to reexamine and reflect the issue of tourism safety education to college students, and it is imperative to carry out tourism safety education for college students.

\section{A Study on Tourism Behavior of College Students}

\subsection{Optional Travel Become the First Choice for College Students}

The first step to do the safety education of college students is to study the travel behavior of post90s college students. Based on the analysis of college students' tourism safety accidents in recent years, we find that university students' autonomy is strong. They are more willing to follow their own plans and preferences to make travel arrangements instead of the stereotyped arrangement. At the same time, affected by economic and media exposure of travel agencies and tour guides, such as compulsory consumption, travel scams and other reports. That makes students choose optional tour 
with less money rather than the travel agencies. For the college students, it has more risk-taking spirit and dream-chasing, which meet their needs better.

\subsection{College students Have a tendency to Choose Non-traditional Tourism Routes}

Surveys show that most of the 90 students from childhood in school organizations or parents led, often go to some famous tourist attractions, to the university, they are more yearning for similar mountaineering, adventure, drifting, bungee jumping and other challenging tourism activities, often participate in various types of "Donkey Friends" club of the outdoor interaction, their social experience less, weak safety awareness, young, full of adventurous spirit, curiosity, more willing to break the time and space limitations, unwilling to adhere to the traditional places of interest, more willing to open a different, Choose some of the untapped or immature tourist attractions, there is a rare, to college students more exciting, more suitable for adventure.

\subsection{The College Students' Awareness of Tourism Safety is Weak and the Ability of Self-help is Poor}

College students are looking forward to adventures and stimulating tourism while the awareness of tourism safety is very weak. As the college students cannot be independent of the economy. The relatively professional travel friends are equipped with expensive outdoor adventure equipment and their equipment is more amateur. They are not very concerned about the transport, accommodation, diet and even the safety factors, and finally choose to camp in the tourist attractions. Due to the lack of safety awareness, college students cannot be aware of the existence of danger. Once the danger occurs, in the absence of any psychological preparation and preparedness, college students will be helpless. Shanghai Jiao tong University students in the event of the speedboat, did not even wear life jackets, indicating that they lack the basic safety knowledge. This proved that the safety awareness of college students, self-protection awareness is not strong once again. The same situation are also revealed in the past security incidents. No knowledge of security and self-help and lack of selfprotection awareness put college students in a certain danger, and once there are uncertainties, it may cause casualties.

\section{Tourism Safety Education Approaches for College Students}

\subsection{Focus on Entrance Education}

Entrance education is the first lesson for college students. Post-90s college students accepted examination oriented education from primary school to secondary school, to the University. With parents and teachers only care about the grades, the students' safety and practice education, on the contrary, are ignored for a long time. Therefore, the ability to deal with the safety and the ability to resist setbacks is even weaker.

Without the pressure of parents and teachers, college students will be more yearning for the freedom of travel when they get into the University. Therefore, the instructor should grasp this chance to stress them the importance of travel safety, remind them of the hidden danger and enhance the knowledge of safety, because the first lesson is always the most impressive. Students should be taught to pay attention to the issue of travel, how to choose the route of travel and how to solve the accident, as these most basic safety knowledge.

\subsection{Strengthen Daily Education}

Students may be difficult to avoid security risks in travel, but the risk can be avoided to most by careful education, organization and management. In daily education, instructors should continue to strengthen the tourism safety education by theme class meetings, lectures, a series of safety activities, knowledge contests, drama and other forms to popularize travel safety knowledge to students and encourage them to actively participate in safety education. For the educational content and educational form, they should be closer to the needs of students and the students real life. For the holidays, instructors should not only focus on improving communication and emergency mechanism, to pay close attention to the whereabouts of the students out, but also keep good communication with the students and parents to know their travel situation, thus we can give necessary guidance and assistance. 
Instructors can establish a tourism association based on the interests of students and reach an agreement with a number of travel agencies, so that students can use the most affordable and safest way to go where they want to go. This can satisfy the desire of students' eager to travel, let the students enrich themselves constantly in the process, broaden their knowledge and vision; on the other hand, it can help the specification and management of college students tourism market.

\subsection{Good Graduation Education}

Graduation tourism, as the most important collective tourism in the university era, has been paid more and more attention. For graduating students, the farewell ceremony before departure is extremely important, graduation ceremony, graduation dinner, graduation tourism, is the graduation ceremony of the trilogy. Graduation travel to relax the pressure of the previous period of time, using a number of photographs on the way to commemorate the university friendship, with the journey of the unforgettable last happy time to make the distinction, has become the most sentimental, the most popular graduation landscape.

Counselor should strengthen the education of graduates' safety. The graduates have plenty of time before they leave, thus the instructors should promote the things that is worth to be considered through grade meeting, qq group, micro-blog, wechat and other network platforms, so that they can Pay attention to the proper safety precautions, choose the regular travel agencies, reduce the probability of tourism safety accidents and prevent college students in the process of tourism in violation of law and discipline, cheated, unexpected phenomenon.

\section{Enhance the Awareness of Tourism Safety and Adaptability of College Students}

The post-90s college students are full of sap, adventure spirit, but little safety awareness and easy to cause personal safety accidents and property safety accidents. In fact, many security risks are controllable. Many unfortunate setbacks are avoidable after comprehensive consideration and active avoidance. Instructors can teach students how to deal with general emergencies during heatstroke, drowning, sprain and other dangerous situations in tourism through elective courses, which can equip them with common sense, enhance students' emergency situation psychological ability and strain capacity.

\section{Conclusion}

An instructor should set up the safety education courses starting with college entrance education, through daily safety education and other aspects of graduate education ways, and put the tourism safety as one of the most important part and let each student learn and master the travel safety knowledge, then, enhance safety awareness, self-protection awareness and prevention awareness, finally the students will learn the methods to deal with sudden situation and danger of self-help. Only by doing that, can they revere the nature and respect life.

In the process of College Students' safety education in the future, newspapers of colleges and uni versities, Internet and other multimedia platform should be used to propagate the information tha $\mathrm{t}$ must pay attention to by the students in tourism and how to choose the time and place of tourism $\mathrm{t}$ o foster college students' safety awareness of tourism and reduce odds of the risk.

Safety is the cornerstone of life and career. The safety education of college students is life educa tion and must be strengthened and improved. So it is significant to understand the security issues an $\mathrm{d}$ their mechanisms existed in college student's tourism and put forward the corresponding counter measure to reduce and prevent the occurrence of travel accidents, which should become an importa nt project of college management. We should improve students' awareness of safety and selfprotection to promote the students' growth and success healthily and safely. The education of touris $\mathrm{m}$ safety in universities and colleges from the view of life is the great concern and love to their stud ents. It is luniversities and national responsibility to ensure the safe of students' travel, which is the source of power for the future development of the motherland, and more attention $\backslash$ must paid to fro $\mathrm{m}$ all levels. 
From the perspective of life, it is the demand for the social development and changes to conduct tourism safety. Education for college students, this is the social change and development for the nee ds of the times. The Universities and colleges should attach much importance to travel security and only in this way can measures be taken effectively. Students' increasing tourism safety awareness an $\mathrm{d}$ effective safety education for them are a common issue before college instructors and teachers, on ly by constant conclusions and thoughts can the solution be figured to adapt to the road match of ed ucation in our country, make students the beneficiaries of the security work, and can the energy of c olleges and universities be put into daily teaching and scientific research.

\section{References}

[1]. Ge Jingbing. Analysis of the management of university students' tourism safety [J]. Heilongjiang Science and Technology information, 2010 (10).

[2]. Liu Minchun. Study on the safety of college students' journeys [J]. Local education theory and practice, 2010 (08).

[3]. Yang Haifeng, Dinning \& Li Shuang. Research on the causes and Countermeasures of college students' travel safety problems [J]. Modern communication, 2013 (01).

[4]. Yu Chunxia. The present situation, problems and countermeasures of college students' tourism [J]. Modern Communication, 2011 (06). 